Active control of flow and heat transfer in silicon microchannels

This content has been downloaded from IOPscience. Please scroll down to see the full text.

2010 J. Micromech. Microeng. 20045006

(http://iopscience.iop.org/0960-1317/20/4/045006)

View the table of contents for this issue, or go to the journal homepage for more

Download details:

IP Address: 159.226.142.161

This content was downloaded on 22/10/2014 at 08:11

Please note that terms and conditions apply. 


\title{
Active control of flow and heat transfer in silicon microchannels
}

\author{
Guohua Liu ${ }^{1}$, Jinliang Xu ${ }^{1,3}$, Yongping Yang ${ }^{2,3}$ and Wei Zhang ${ }^{2}$ \\ ${ }^{1}$ Micro Energy System Laboratory, Guangzhou Institute of Energy Conversion, Chinese Academy of \\ Science, Guangzhou 510640, People's Republic of China \\ ${ }^{2}$ Beijing Key Laboratory of New and Renewable Energy, North China Electric Power University, \\ Beijing 102206, People's Republic of China \\ E-mail: xjl@ncepu.edu.cn and yyp@ncepu.edu.cn
}

Received 27 November 2009, in final form 3 February 2010

Published 5 March 2010

Online at stacks.iop.org/JMM/20/045006

\begin{abstract}
Boiling heat transfer in silicon microchannels needs high walls and liquid superheats for bubble nucleation, leading to a strong thermal non-equilibrium between vapor and liquid phases, which not only damages the heat transfer device at the start-up stage, but also causes two-phase flow instabilities. In this paper, the seed bubble technique is used as an active control strategy to improve the flow and heat transfer in silicon microchannels. Seed bubbles are miniature bubbles of micron size, which are produced on a set of microheaters upstream of microchannels driven by pulse voltage signal. They flow downstream of microchannels after they depart from microheaters to decrease and control the thermal non-equilibrium between vapor and liquid phases in microchannels. The working fluid was methanol and the hydraulic diameter of the microchannels was $100 \mu \mathrm{m}$. The demand curves of pressure drops versus mass fluxes were examined with and without active control. Four regions (I, II, III and IV) of demand curves were identified. For the flow without active control, the four regions were the subcooled liquid flow, the superheated liquid flow, the unstable boiling flow and the vapor flow at high-vapor-mass qualities. Alternatively, for the flow with active control, the four regions were the subcooled liquid flow, the seed-bubble-triggered boiling flow, the seed-bubble-stabilized boiling flow and the vapor flow at high-vapor-mass qualities. The linear part of the demand curves is shortened when the seed bubble technique is used. The points at which the demand curves deviate from the linear part coincide into one point at different seed bubble frequencies. The seed bubbles have no influence on the subcooled liquid flow (region I) and the vapor flow at high-vapor-mass qualities (region IV). However, seed bubbles not only convert a superheated liquid flow into a quasi-stable boiling flow in region II, but also convert an unstable boiling flow into a quasi-stable boiling flow in region III. Besides, heat transfer coefficients with active control are several times those without active control in regions II and III. The higher the seed bubble frequencies, the more the heater surface temperatures decrease.
\end{abstract}

(Some figures in this article are in colour only in the electronic version)

\section{Nomenclature}

$A$

$A_{W}$

Bo

$C_{\mathrm{pf}}$

$C_{\mathrm{pg}}$

3 Author to whom any correspondence should be addressed.

microheater surface area, $\mu \mathrm{m}^{2}$ main heater surface area, $\mu \mathrm{m}^{2}$ boiling number specific heat of liquid, $\mathrm{J} \mathrm{kg}^{-1} \mathrm{~K}^{-1}$ specific heat of vapor, $\mathrm{J} \mathrm{kg}^{-1} \mathrm{~K}^{-1}$

$0960-1317 / 10 / 045006+16 \$ 30.00$ $f$

$G$

$h_{\text {film }}$

$h_{\mathrm{fg}}$

$k_{\mathrm{f}}$

$m$

$N$

OFI

ONB seed bubble frequency, $\mathrm{Hz}$

mass flux in microchannels, $\mathrm{kg} \mathrm{m}^{-2} \mathrm{~s}^{-1}$ heat transfer coefficient, $\mathrm{W} \mathrm{m}^{-2} \mathrm{~K}^{-1}$ latent heat of evaporation, $\mathrm{J} \mathrm{kg}^{-1}$ thermal conductivity of liquid, $\mathrm{W} \mathrm{mK} \mathrm{m}^{-1}$ mass flow rate, $\mathrm{kg} \mathrm{s}^{-1}$ number of microchannels onset of flow instability onset of nucleate boiling 


\begin{tabular}{|c|c|}
\hline$\Delta p$ & pressure drop, $\mathrm{Pa}$ \\
\hline$q$ & heat flux at the main heater surface, $\mathrm{W} \mathrm{m}^{-2}$ \\
\hline$q_{\mathrm{fi}}$ & heat flux at the microheater surface, $\mathrm{W} \mathrm{m}^{-2}$ \\
\hline$q_{\mathrm{s}}$ & $\begin{array}{l}\text { heat flux based on two side walls of } \\
\text { microchannels, } \mathrm{W} \mathrm{m}^{-2}\end{array}$ \\
\hline$Q$ & $\begin{array}{l}\text { heating power on the microheaters produced } \\
\text { by the pulse voltage signal, } \mathrm{W}\end{array}$ \\
\hline$R_{\mathrm{Au} 1}$ and $R_{\mathrm{Au} 2}$ & two gold pad resistances, $\Omega$ \\
\hline$R_{\mathrm{e}}$ & seed bubble radius, $\mathrm{m}$ \\
\hline$R_{\mathrm{f}}$ & given resistance, $\Omega$ \\
\hline$R_{\mathrm{s}}$ & $\begin{array}{l}\text { resistance selected from the standard } \\
\text { resistance box, } \Omega\end{array}$ \\
\hline$T_{\mathrm{c}}$ & critical temperature of fluid, ${ }^{\circ} \mathrm{C}$ \\
\hline$T_{\mathrm{f}}$ & fluid temperature, ${ }^{\circ} \mathrm{C}$ \\
\hline$T_{\mathrm{fi}}$ & microheater temperature, ${ }^{\circ} \mathrm{C}$ \\
\hline$T_{\text {film }}$ & $\begin{array}{l}\text { main heater surface temperature at } x_{\text {film }}= \\
8.0 \mathrm{~mm},{ }^{\circ} \mathrm{C}\end{array}$ \\
\hline$T_{\text {film,c }}$ & temperature at the main heater centerline, ${ }^{\circ} \mathrm{C}$ \\
\hline$T_{\text {sat }}$ & saturation temperature, ${ }^{\circ} \mathrm{C}$ \\
\hline$T_{\mathrm{W}, \max }$ & $\begin{array}{l}\text { maximum temperature at the main heater } \\
\text { surface, }{ }^{\circ} \mathrm{C}\end{array}$ \\
\hline$t$ & time, $\mathrm{s}$ \\
\hline$V_{1}$ and $V_{2}$ & $\begin{array}{l}\text { voltages in the microheater circuit (see } \\
\text { figure } 2 \text { ), } \mathrm{V}\end{array}$ \\
\hline$V_{3}$ and $V_{4}$ & $\begin{array}{l}\text { voltages in the main heater circuit (see } \\
\text { figure } 2 \text { ), } V\end{array}$ \\
\hline$x$ and $y$ & $\begin{array}{l}\text { coordinates in the axial and width directions } \\
\text { (see figure } 1 \text { ), } \mathrm{m}\end{array}$ \\
\hline$x_{\text {film }}$ and $y_{\text {film }}$ & $\begin{array}{l}\text { attached coordinate on the main heater (see } \\
\text { figure } 1), m\end{array}$ \\
\hline$\phi$ & thermal efficiency \\
\hline$\varphi$ & heat transfer enhancement ratio \\
\hline$\mu_{\mathrm{f}}$ & viscosity of liquid, $\mathrm{Pa} \mathrm{s}$ \\
\hline$\mu_{\mathrm{g}}$ & viscosity of vapor, $\mathrm{Pa} \mathrm{s}$ \\
\hline$\rho_{\mathrm{f}}$ & liquid density, $\mathrm{kg} \mathrm{m}^{-3}$ \\
\hline$\sigma$ & surface tension, $\mathrm{N} \mathrm{m}^{-1}$ \\
\hline$\tau$ & pulse duration time, $\mathrm{s}$ or $\mathrm{ms}$ \\
\hline
\end{tabular}

\section{Introduction}

Boiling heat transfer in microchannels has recently received great attention, due to its wide application in electronic industries. Lin et al (1998) measured the roughness of a polysilicon microheater surface by an atomic force microscope (AFM) and found that the roughness was $6.5 \mathrm{~nm}$, which is almost the same size as the curvature of the critical bubble nucleus $r_{\mathrm{c}}$ for homogeneous nucleation, which equals $3.15 \mathrm{~nm}$ for water ( $\mathrm{Li}$ and Cheng 2004). Bubble nucleation in smooth silicon microchannels is either a homogeneous process or a heterogeneous process on the surface with micro-/nanocavities. Wall superheat at the onset of nucleate boiling (ONB) is significantly high. Kandlikar et al (1997) calculated the flow over a bubble attached to a channel wall at a given contact angle and gave a bubble nucleation criterion, representing the lowest temperature at which a cavity of a given size will nucleate. The cavities will continue to nucleate at higher superheats. If cavities of this radius are not available, the onset of nucleation will be delayed into the downstream of the channel until the wall superheat meets the bubble nucleation criterion. Kandlikar (2002) discussed fundamental issues related to flow boiling in microchannels. Liu et al (2005) developed an analytical model to predict the incipient heat flux and the bubble size at the onset of boiling. The closed-form solution obtained reflects the impact of the important running parameters on the incipient heat flux. The microchannels in their studies were $275 \mu \mathrm{m}$ wide $\times 636 \mu \mathrm{m}$ deep, and water was the working fluid. Kandlikar et al (2006) noted that wall superheats at the ONB are quite high in microchannels, even in the presence of right-sized cavities. The introduction of artificial cavities on channel wall surfaces alone may not be enough to suppress flow instabilities due to the rapid bubble growth. Thus, they proposed the hybrid technique of pressure drop elements and fabricated nucleation sites to suppress flow instabilities in microchannels. Yu et al (2006) investigated pool boiling heat transfer using an artificial micro-cavity surface immersed in FC-72 liquid. Wall superheats could reach several tens of degrees at the boiling incipience even though micro-cavities were used.

It is found that flow instabilities in microchannels are strongly related to the high boiling incipience temperature (Xu et al 2009). We consider liquid flow in microchannels if heating power is increased continuously. The bubble nucleation does not occur until wall and liquid superheats are sufficiently high. Once boiling incipience takes place, the superheated liquid releases its stored energy to vapor in a short time. A sharp pressure increase in the vapor core makes the fluid travel in both downstream and upstream directions. The vapor growth and pressure rise stage is over when the superheated liquid completely releases its stored energy. The incoming fresh liquid refills microchannels due to the external pumping power. It needs a long waiting time for the incoming liquid to reach the superheated bubble nucleation temperature again. The above processes are repeated in time sequence, causing the alternating flow pattern transitions in microchannels.

Thome and Dupont (2007), in their patent, proposed a heat transfer assembly design, consisting of an evaporator and a bubble generator connected by a tube. Recently, $\mathrm{Xu}$ et al (2009) used seed bubbles to stabilize flow and heat transfer in microchannels. The oscillating boiling heat transfer is sustained in microchannels without the assistance of seed bubbles. Seed bubbles at low frequencies shorten the oscillating cycle periods and decrease the oscillating amplitudes of pressure drops and heating surface temperatures. High-frequency $(f>50 \mathrm{~Hz})$ seed bubbles completely suppress flow instabilities.

The objective of this study is to examine the demand curves of pressure drops versus mass fluxes with and without active control. The seed bubble technique is used as an effective control strategy. Methanol was used as the working fluid. Experiments were performed over a wide range of mass fluxes for different heat fluxes. It is found that the demand curves can be divided into four regions. The linear part of the demand curves is shortened by the seed bubbles. Seed bubbles have no effect on the subcooled liquid flow and the vapor flow at high-vapor-mass qualities. However, seed bubbles not only 

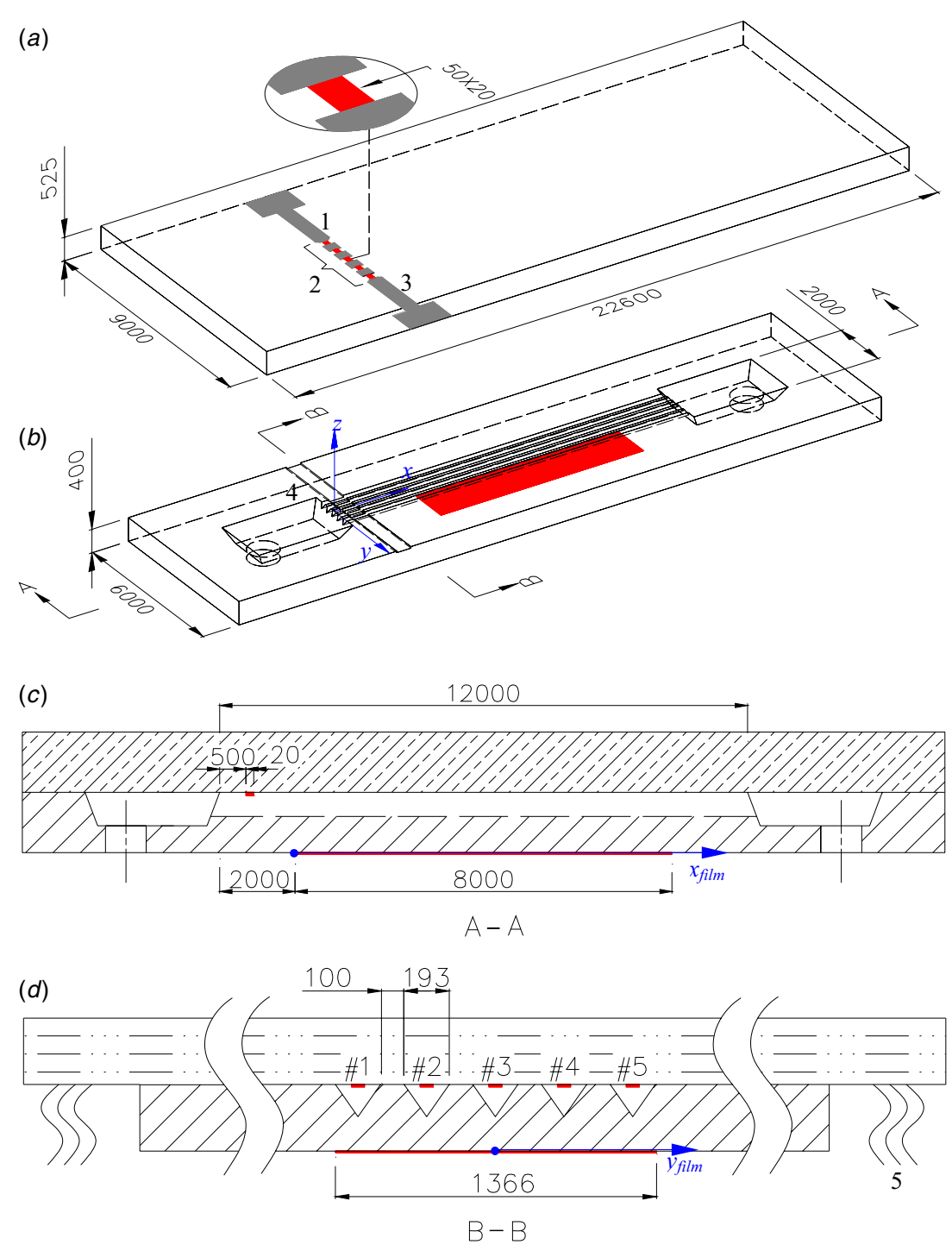

Figure 1. The seed-bubble-guided heat transfer system; all dimensions are in $\mu \mathrm{m} .1$ and 3: resistances of gold pads $\left(R_{\mathrm{Au} 1}\right.$ and $\left.R_{\mathrm{Au} 2}\right) ; 2$ : resistance of the five microheaters $\left(R_{\mathrm{fi}}\right) ; 4$ : bonding channel with the depth of $1.5 \mu \mathrm{m}$ to suspend the gold pad; 5 : signal wire for the seed bubble generations. The red rectangular area in $(b)$ is the effective heating area at the back surface of silicon substrate, and the design is similar to that in Xu et al (2009), except that the length of the main heater is $8.0 \mathrm{~mm}$ instead of $4.5 \mathrm{~mm}$ in Xu et al (2009).

convert a superheated liquid flow into a quasi-stable boiling flow, but also convert an unsteady boiling flow into a quasistable boiling flow. A significant heat transfer enhancement was observed in regions II and III. The higher the seed bubble frequency, the more the heater surface temperatures decrease.

\section{Description of the experiment}

\subsection{The test section and experimental setup}

Figure 1 shows the silicon microchannel heat sink integrated with seed bubble generators in the microchannel upstream. The whole microsystem had a length of $22.6 \mathrm{~mm}$ and a width of $9.0 \mathrm{~mm}$. The top 7740 glass cover (thickness of $525 \mu \mathrm{m}$ ) and the bottom silicon substrate (thickness of $400 \mu \mathrm{m}$ ) were bonded together. Five triangular microchannels with a hydraulic diameter of $100 \mu \mathrm{m}$ were etched in the silicon substrate. They had the length of $12000 \mu \mathrm{m}$, covering the total width of $1366 \mu \mathrm{m}$. At the back surface of the silicon substrate, a rectangular area (represented by the red area in figure $1(b)$ ) was deposited by the platinum film as the main heater. The effective deposition area is $8000 \mu \mathrm{m}$ in length and $1366 \mu \mathrm{m}$ in width. A dc voltage is applied on the main heater acting as the heating source. The present design is similar to that in $\mathrm{Xu}$ et al (2009), except that the length of the main heater is $8.0 \mathrm{~mm}$, instead of $4.5 \mathrm{~mm}$ as in Xu et al (2009).

Cross sections of $\mathrm{A}-\mathrm{A}$ and $\mathrm{B}-\mathrm{B}$ referring to figure $1(b)$ are shown in figures $1(c)$ and $(d)$. At the microchannel entrance, a coordinate system was established, with $x, y$ and $z$ as the axial flow direction, the chip width and the chip thickness direction, respectively (see figure 1(b)). Another two-dimensional attached coordinate system $\left(x_{\text {film }}, y_{\text {film }}\right)$ was set on the main heater surface $\left(8000 \times 1366 \mu \mathrm{m}^{2}\right)$, with $x_{\text {film }}=0$ as the beginning of the heating area and $y_{\text {film }}=0$ at the centerline of the heating area. 
(a)

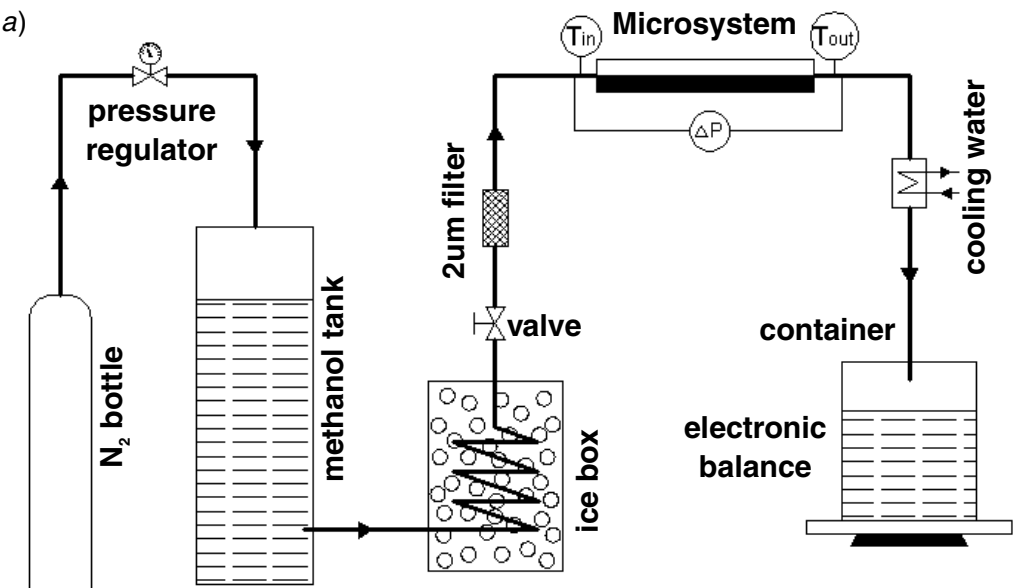

(b)

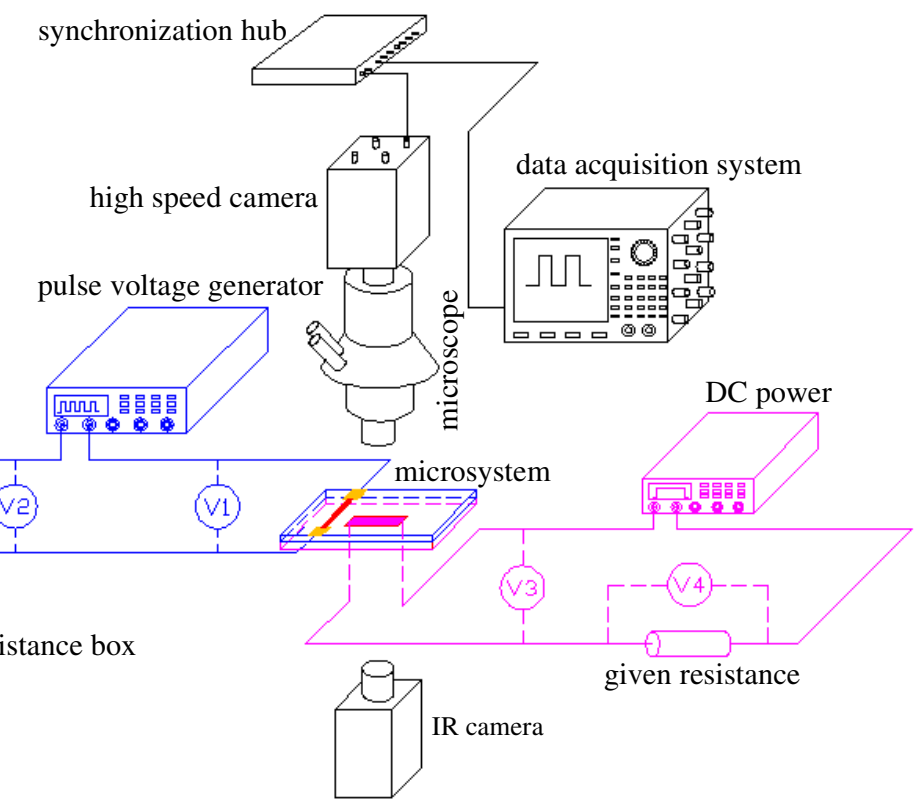

Figure 2. The forced convection loop $(a)$ and measurement system $(b)$. Note that the flow system shown in $(a)$ is different from that in $\mathrm{Xu}$ et al (2009), but the measurement system in (b) is the same as that in Xu et al (2009).

Different from other studies of microchannel heat sinks reported in the literature, an active control method was used to improve the flow and heat transfer performance in this paper. As shown in figure 1(a), five microheaters are fabricated at the back surface of the glass cover, each having a size of $50 \times 20 \mu \mathrm{m}^{2}$. They are within microchannels, located $500 \mu \mathrm{m}$ away from the microchannel entrance along the flow direction (see figure $1(c)$ ). Each microheater corresponds to a specific channel, marked as \#1 to \#5 consecutively (see figure $1(d)$ ). Pulse voltage signals were applied on the microheaters to generate seed bubbles to control the flow and heat transfer in microchannels.

Figure 2(a) shows the experimental setup. The pumping flow rate of methanol was driven by a high-pressure nitrogen gas, which is different from our previous study in which the flow rate was provided by a syringe pump (Xu et al 2009). The flow system consists of a nitrogen gas bottle, a valve regulator, a pressure (methanol) tank, an ice box, a $2 \mu \mathrm{m}$ filter, the test section and a heat exchanger. The liquid was finally collected in a container (beaker) weighted by an electronic balance.

The measurement system is shown in figure $2(b)$, consisting of three parts. The blue part represents the seed bubble generation. The microheater array was driven by a pulse voltage signal, with the pulse frequency $f$ ranging from 0.2 to $20 \mathrm{MHz}$ and the output voltage amplitude ranging from 0 to $20 \mathrm{~V}$. The red part shows the power supplier to the main heater at the back surface of the wafer. In such a circuit, a given electronic resistance is included. The black part consists of a high-speed camera bonded with a microscope to record the flow pattern image, an IR image system for the temperature measurement at the back surface of the silicon substrate and a high-speed data acquisition system for all the thermocouples, pressures and other voltage signal measurement. The detailed description of the whole measurement system can be found in $\mathrm{Xu}$ et al (2009). 
Table 1. Major physical properties of methanol at atmospheric pressure.

\begin{tabular}{|c|c|c|c|c|c|c|c|c|c|}
\hline$T_{\text {sat }}\left({ }^{\circ} \mathrm{C}\right)$ & $\rho_{\mathrm{f}}\left(\mathrm{kg} \mathrm{m}^{-3}\right)$ & $C_{\mathrm{pf}}\left(\mathrm{kJ} \mathrm{kg}^{-1} \mathrm{~K}^{-1}\right)$ & $C_{\mathrm{pg}}\left(\mathrm{kJ} \mathrm{kg}^{-1} \mathrm{~K}^{-1}\right)$ & $h_{\mathrm{fg}}\left(\mathrm{kJ} \mathrm{kg}^{-1}\right)$ & $\mu_{\mathrm{f}}(\mathrm{Pa} \mathrm{s})$ & $\mu_{\mathrm{g}}(\mathrm{Pa} \mathrm{s})$ & $k_{\mathrm{f}}\left(\mathrm{W} \mathrm{mK}^{-1}\right)$ & $\sigma\left(\mathrm{N} \mathrm{m}^{-1}\right)$ & $T_{\mathrm{c}}\left({ }^{\circ} \mathrm{C}\right)$ \\
\hline 64.70 & 790 & 2.49 & 1.41 & 1150 & $5.39 \times 10^{-4}$ & $9.63 \times 10^{-6}$ & 0.52 & 0.0221 & 239.58 \\
\hline
\end{tabular}

$T_{\text {sat }}$ : saturation temperature; $\rho_{\mathrm{f}}$ : liquid density; $C_{\mathrm{pf}}$ and $C_{\mathrm{pg}}$ : specific heats of liquid and vapor; $h_{\mathrm{fg}}$ : latent heat of evaporation; $\mu_{\mathrm{f}}$ and $\mu_{\mathrm{g}}$ : viscosities of liquid and vapor; $k_{\mathrm{f}}$ : thermal conductivity of liquid; $\sigma$ : surface tension; $T_{\mathrm{c}}$ : critical temperature.

\subsection{Parameter measurements and data reduction}

Pure methanol liquid $\left(\mathrm{CH}_{3} \mathrm{OH}\right.$, purity more than $\left.99.5 \%\right)$ was used in this study. The saturation temperature is $64.7{ }^{\circ} \mathrm{C}$ at atmospheric pressure and the critical temperature is $239.58^{\circ} \mathrm{C}$. The major physical properties are shown in table 1 , cited from Yaws (1999). Parameter measurements involve inlet and outlet temperatures of microchannels, surface temperatures at the main heater surface and the pressure drop across the test section. Inlet and outlet temperatures were measured by two K-type thermocouples having diameters of $0.1 \mathrm{~mm}$ with a response time of $0.1 \mathrm{~s}$. Main heater surface temperatures were measured by the IR imaging system.

The data reduction process involves a set of parameters, which are described as follows.

Mass flux. The mass flux $(G)$ is the mass flow rate divided by the total cross-sectional area of the five microchannels, i.e. $G=m /\left(N A_{\mathrm{c}}\right)$, where $m$ is the mass flow rate, $N$ is the number of microchannels and $A_{\mathrm{c}}$ is the cross-sectional area of a single microchannel.

Heat flux. The heat flux $(q)$ was computed as $q=$ $\phi V_{3} V_{4} /\left(R_{\mathrm{f}} A_{W}\right)$, where $V_{3}$ and $V_{4}$ are the voltages shown in figure $2, A_{W}$ is the main heater surface area, $R_{\mathrm{f}}$ is the given resistance (see figure 2 ) and $\phi$ is the thermal efficiency.

Thermal efficiency. A set of liquid flow and heat transfer experiments were performed to determine the effective thermal efficiency, which is defined as the effective enthalpy increment across the test section divided by the total heating power. The value of the thermal efficiency ranges from 0.75 to 0.87 . Thus, the average value of 0.81 was used to compute the effective heating power on the main heater surface.

Boiling number. Boiling number (Bo) was defined as $B o=q /\left(G h_{\mathrm{fg}}\right)$, where $h_{\mathrm{fg}}$ is the latent heat of evaporation.

Heat transfer coefficient. Because heat transfer coefficient may be varied along the flow direction, it is defined at the end of the effective heating length, i.e. at $x_{\text {film }}=$ $8.0 \mathrm{~mm}$ (see figure $1(c)$ ), at which temperatures attain almost maximum values. Heat transfer coefficient is written as $h_{\text {film }}=q_{\mathrm{s}} /\left(T_{\mathrm{film}}-T_{\mathrm{f}}\right)$, where $q_{\mathrm{s}}$ is the heat flux based on the two side wall's surface area with the heating length of $8.0 \mathrm{~mm}, T_{\text {film }}$ is the main heater surface temperature at $x_{\text {film }}=8.0 \mathrm{~mm}$ and $T_{\mathrm{f}}$ is the fluid temperature. For boiling flow, $T_{\mathrm{f}}$ should be the saturation temperature at the local pressure.

Heat transfer enhancement ratio. In order to evaluate the effectiveness of the active control method reported in this paper, a heat transfer enhancement ratio is defined as $\Phi=$ $h_{\text {film,f }} / h_{\text {film,f }}=0$, where $h_{\text {film,f }}$ is the heat transfer coefficient with active control at the pulse voltage frequency $f$ and
Table 2. The parameter uncertainties or relative error.

\begin{tabular}{llll}
\hline & $\begin{array}{l}\text { Uncertainty or } \\
\text { Parameter }\end{array}$ & $\begin{array}{l}\text { Uncertainty or } \\
\text { relative error }\end{array}$ \\
\hline$A\left(\mu \mathrm{m}^{2}\right)$ & 0.1 & $T_{\text {in }}$ and $T_{\text {out }}\left({ }^{\circ} \mathrm{C}\right)$ & 0.3 \\
$A_{W}\left(\mu \mathrm{m}^{2}\right)$ & 0.1 & $T_{\text {film }}\left({ }^{\circ} \mathrm{C}\right)$ & 0.5 \\
$B o(\%)$ & 7.0 & $T_{\text {film,c }}\left({ }^{\circ} \mathrm{C}\right)$ & 0.5 \\
$F(\%)$ & 0.001 & $V_{1}$ and $V_{2}(\mathrm{mV})$ & 0.1 \\
$G(\%)$ & 1.5 & $V_{3}$ and $V_{4}(\mathrm{mV})$ & 0.1 \\
$M(\%)$ & 1.2 & $x$ and $y(\mu \mathrm{m})$ & 0.1 \\
$Q(\%)$ & 6.0 & $x_{\text {film }}$ and $y_{\text {film }}(\mu \mathrm{m})$ & 0.1 \\
$q_{\mathrm{fi}}(\%)$ & 5.0 & $h_{\text {film }}(\%)$ & 7.0 \\
$q_{\mathrm{s}}(\%)$ & 6.0 & $\phi(\%)$ & 6.0 \\
$R_{\mathrm{Au} 1 \text { and }}$ & 1.0 & $\varphi(\%)$ & 7.0 \\
$R_{\mathrm{Au} 2}(\%)$ & & & 0.1 \\
$R_{\mathrm{f}}(\%)$ & 1.0 & $\Delta p(\%)$ & 100 \\
$R_{\mathrm{s}}(\%)$ & 0.1 & $\tau(\mathrm{ns})$ & \\
$T_{\mathrm{fi}}\left({ }^{\circ} \mathrm{C}\right)$ & 2 & & \\
\hline
\end{tabular}

$h_{\text {film,f }}=0$ is the heat transfer coefficient without active control.

The calibration was performed to determine the electric resistance of microheaters versus temperatures. During such a calibration, the microchannel heat sink assembly was put in an oven with a well-controlled temperature having an uncertainty of $0.5{ }^{\circ} \mathrm{C}$. The temperature ranges from 20 to $120{ }^{\circ} \mathrm{C}$. A linear relationship between the microheater resistances and temperatures was obtained as $R_{\mathrm{fi}}=0.0421 T_{\mathrm{fi}}+24.869$. The dynamic heating power on the microheaters was calculated as

$$
Q(t)=\left(\frac{V_{2}(t)}{R_{\mathrm{s}}}\right)^{2}\left(\frac{V_{1}(t)}{V_{2}(t)} R_{\mathrm{s}}-R_{\mathrm{Au} 1}-R_{\mathrm{Au} 2}\right)
$$

where $V_{1}(t)$ and $V_{2}(t)$ are the instantaneous voltages in the pulse voltage circuit (see the blue part in figure 2 ), $R_{\mathrm{s}}$ is the precise resistance selected from the standard resistance box and $R_{\mathrm{Au} 1}$ and $R_{\mathrm{Au} 2}$ are the two gold pad resistances (see figure $1(a)$ ), with $R_{\mathrm{Au} 1}=R_{\mathrm{Au} 2}=0.958 \Omega$ at room temperature. The heat flux on the five platinum microheater surfaces is calculated by $q_{\mathrm{fi}}(t)=Q(t) /(N A)$, where $N$ is the number of microheaters and $A$ is the microheater surface area, which equals $50 \times 20 \mu \mathrm{m}^{2}$. The parameter uncertainties are summarized in table 2 .

\section{Experimental procedure}

The objective of this paper is to examine the demand curves of pressure drops versus mass fluxes at different heating powers at the main heater surface with and without active control. The runs cover a wide range of mass fluxes and thus liquid flow, boiling flow, and nearly dried-out state may appear in microchannels. Thus, we can obtain a full picture of the seedbubble-guided flow and heat transfer in microchannels. The experimental procedure is as follows. 


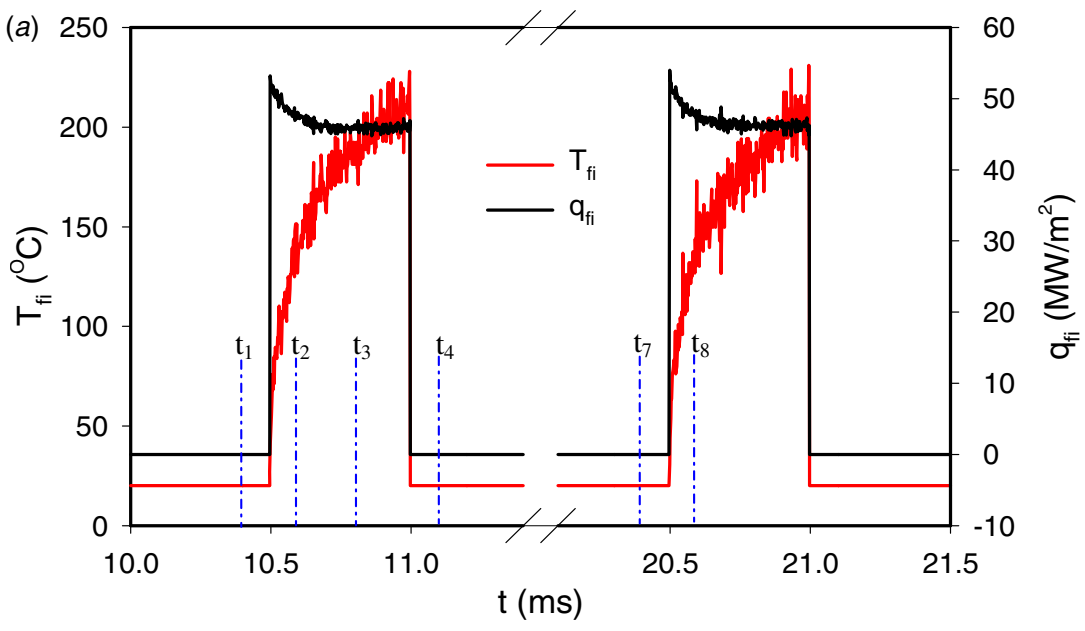

(b)

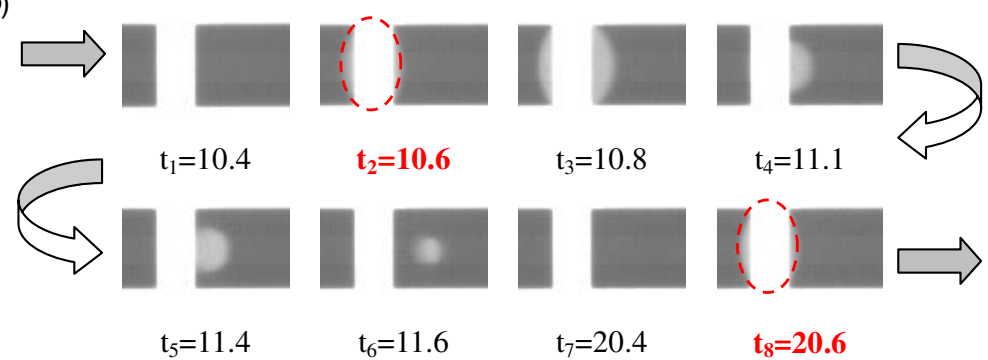

Figure 3. The transient temperature and the heat flux on the microheater for seed bubble generation $(a)$ and the periodic seed bubble generation and departure on the \#3 microheater surface $(b)$ (time unit is $\mathrm{ms} ; G=517.89 \mathrm{~kg} \mathrm{~m}^{-2} \mathrm{~s}^{-1} ; q=374.61 \mathrm{~kW} \mathrm{~m}{ }^{-2} ; B o=0.000629$; $f=100 \mathrm{~Hz} ; \tau=10 \mathrm{~ms})$.

(1) The degassed methanol is charged and the pressure in the liquid tank is adjusted.

(2) The mass flux in microchannels is regulated at the adiabatic condition without applying heating power on the main heater surface. After the system reaches a steady state, parameters such as pressure drop, mass flux, etc are recorded.

(3) Step 2 is repeated with mass fluxes gradually changing from very high values to low values. Repeating steps 2 and 3 yields the demand curves of pressure drops versus mass flux at the adiabatic condition.

(4) At the flowing state, a predetermined heating power was applied on the main heater surface. Such a heating power is not changed until a pair of runs with and without active control is over.

(5) Runs started from a very high mass flux without active control, i.e. seed bubbles are turned off. The parameters are recorded once the steady state (or steady-oscillation state) is reached, noting that flow pattern images are also recorded when the run is in two-phase state.

(6) Step 5 is repeated with active control, i.e. seed bubbles are turned on. All the related parameters and images are recorded.

(7) Steps 5 and 6 are repeated for a decreased mass flux, until a very low mass flux is reached.

(8) Steps 4-7 are repeated for another heating power on the main heater surface.

Using the above procedure, the demand curves of pressure drops against the mass fluxes are obtained with and without active control, including the adiabatic state. Flow and heat transfer performance is compared among the runs with and without active control. The data in this paper had the following values: heat fluxes on the main heater surface, $0-375 \mathrm{~kW} \mathrm{~m}^{-2}$; mass fluxes, $100-1200 \mathrm{~kg} \mathrm{~m}^{-2} \mathrm{~s}^{-1}$; seed bubble frequencies, 0-1000 Hz; inlet liquid temperatures, $3-5{ }^{\circ} \mathrm{C}$; and pressure drops, $1-18 \mathrm{kPa}$. The exit of microchannel heat sink always had atmospheric pressure.

\section{Results and discussion}

\subsection{Seed bubble generation and departure}

Usually, a normal bubble is a bubble that is nucleated locally and grows to form a large bubble. In this paper, the bubble nucleation and growth are separated into two independent processes. Seed bubbles are produced on microheaters by pulse voltage signal, having the size of micron. They flow downstream of microchannels and grow once they contact the superheated liquid. The seed bubble frequency equals the pulse voltage frequency; thus, seed bubbles are well controlled. Bubble dynamics on a small-scale microheater surface under the pulse heating condition has been widely studied for ink-jet applications. However, bubble dynamics on microheaters in microchannels under flow condition is less reported in the literature. Generally, the heat flux on the microheaters is high to activate the bubble generation. When the pulse voltage signal is on during a pulse cycle, microheaters have higher temperatures than those of the surrounding solid 

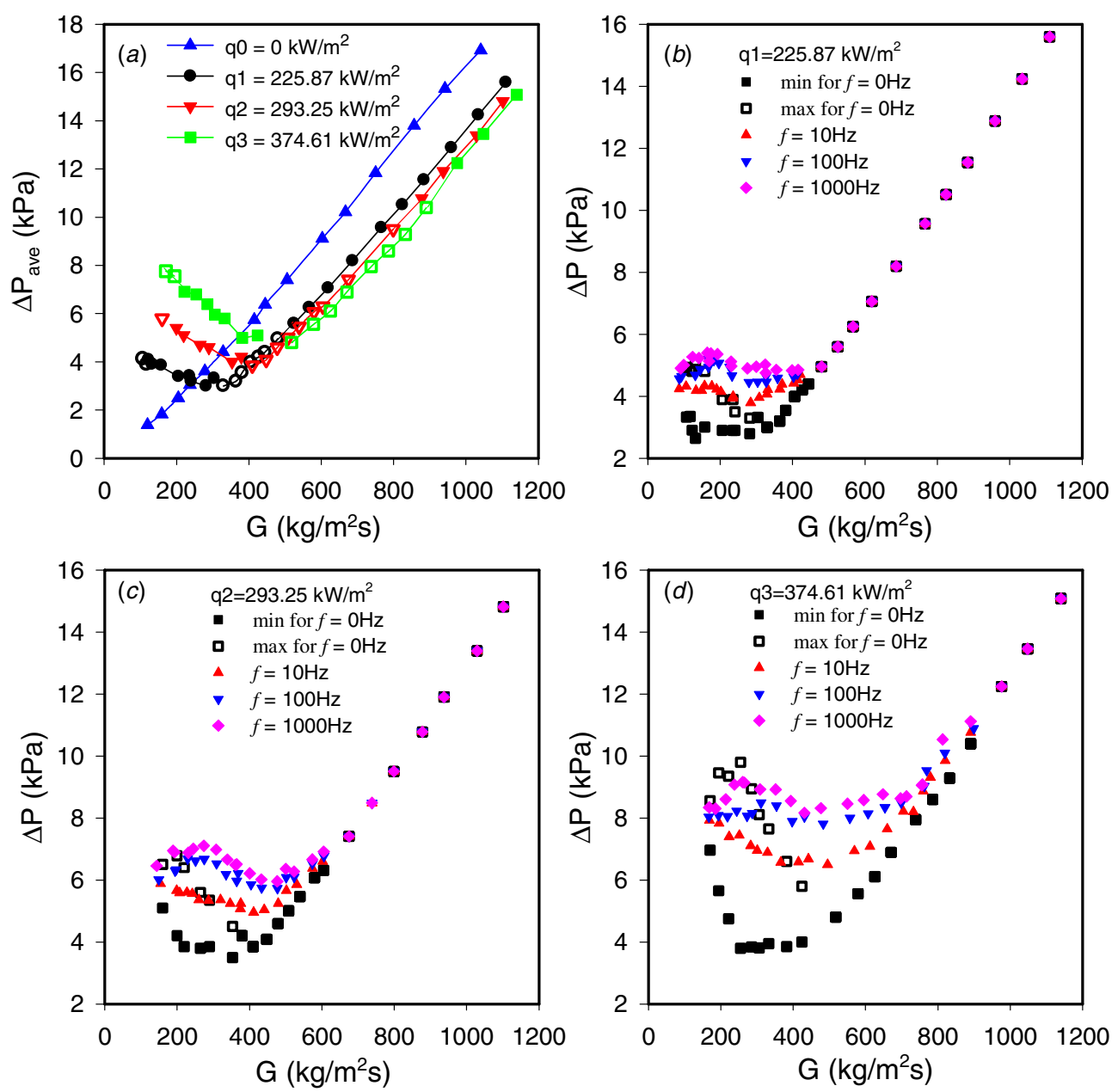

Figure 4. Demand curves of pressure drops versus mass fluxes for the three heat fluxes with and without active control.

and liquid; thus, seed bubbles are on the microheater surfaces due to the Marangoni effect. Once the pulse voltage signal is off during the pulse cycle, microheaters recede to the liquid temperature quickly; thus, the Marangoni effect disappears. A shear force from the flowing liquid stream $\left(4 \pi \mu_{\mathrm{f}} R_{\mathrm{e}} \sim 1 \mathrm{mN}\right)$ flushes seed bubbles away from microheaters, where $R_{\mathrm{e}}$ is the seed bubble radius. Consecutive pulses control the seed bubble generation and departure.

Figure 3(a) shows temperatures and heat fluxes on the microheater surface for the pulse frequency of $100 \mathrm{~Hz}$. The pulse cycle period is $10 \mathrm{~ms}$. The mass flux is $517.89 \mathrm{~kg} \mathrm{~m}^{-2} \mathrm{~s}^{-1}$. The heat flux on the main heater surface is $374.61 \mathrm{~kW} \mathrm{~m}^{-2}$, which does not affect the seed bubble generation and departure. The microheater temperatures increase gradually once a pulse is on and attain maximum values of about $220-230{ }^{\circ} \mathrm{C}$ at the end of the pulse. The heat flux on the microheaters sharply increases to $53 \mathrm{MW} \mathrm{m}^{-2}$ and then slightly decreases due to the varying microheater resistance versus temperature. Specific time is marked in figure 3(a) for $t_{1}, t_{2}, t_{3}$ and $t_{4}$, where $t_{1}$ is the time before a pulse begins, $t_{2}$ and $t_{3}$ are on the pulse and $t_{4}$ is the time after a pulse recedes. Figure 3(b) shows seed bubble generation and departure. No bubble is observed at $t=t_{1}$ and a bubble is seen on the microheater surface at $t=t_{2}$. The seed bubble departs from the microheater at $t>t_{4}$, and is thoroughly away from the microheater at $t>t_{5}$. Another bubble is seen at $t=t_{8}$ for the next pulse.

Even though the instantaneous heat flux on microheaters is sufficiently high, the average heating power on the microheaters is in the order of milliwatts, which is sufficiently lower than the heating power applied on the main heater at the back surface of the silicon substrate.

Theoretically active control of flow and heat transfer in microchannels needs very small seed bubbles. However, very small seed bubbles may be fully condensed before they reach the saturated or the superheated liquid in microchannels due to the subcooled liquid in the inlet. It is observed that seed bubbles with the size of $\sim 10 \mu \mathrm{m}$ are not fully condensed in microchannels; thus, they are effective for the active control of flow and heat transfer in microchannels.

\subsection{Demand curves of pressure drops versus mass fluxes with and without active control}

Figure 4 shows demand curves of pressure drops versus mass fluxes at $q=0$ for the adiabatic condition, and at $q=225.87$, 293.25 and $374.61 \mathrm{~kW} \mathrm{~m}^{-2}$ for heating conditions. The seed bubble frequencies are $f=0$ without active control, and 10,100 and $1000 \mathrm{~Hz}$ with active control. Figure 4(a) plots the average pressure drop against mass fluxes without 

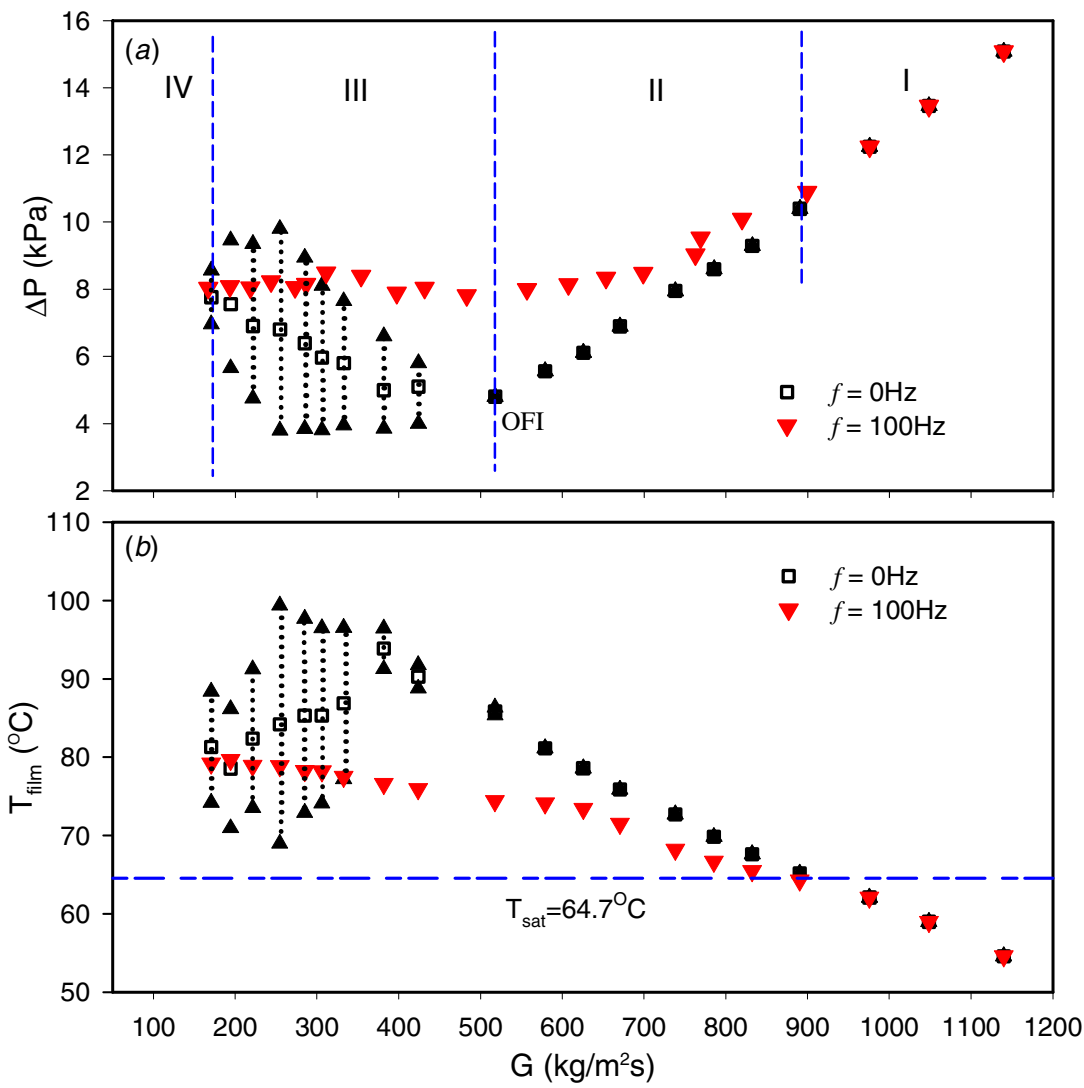

Figure 5. Demand curves of pressure drops versus mass fluxes without $(f=0 \mathrm{~Hz})$ and with active control $(f=100 \mathrm{~Hz})(a)$ and temperatures at the main heater surface at $x_{\mathrm{film}}=8 \mathrm{~mm}(b)\left(q 3=374.61 \mathrm{~kW} \mathrm{~m}^{-2}\right)$.

active control. The average pressure drop is one half of the maximum and the minimum values detected by the pressure drop transducer. The adiabatic condition $(q=0)$ behaves as a perfect linear demand curve due to the constant liquid viscosity along the whole flow length. Under the heating condition, the pressure drops decreased quasi-linearly, attained the minimum value and then increased, with continuous decrease of mass fluxes, thus behaving similar to the typical demand curves reported in the literature (Wu et al 2006, Kuo and Peles $2009)$. Figures $4(b)-(d)$ illustrate the comparisons of demand curves with and without active control for the heat fluxes of $225.87,293.25$ and $374.61 \mathrm{~kW} \mathrm{~m}^{-2}$, respectively, noting that the vertical coordinate is the pressure drop, and not the average pressure drop. The three subfigures have the following characteristics.

- Under the heating condition without active control $(f=0)$, pressure drops decrease quasi-linearly and then switch divaricately to a maximum value, which is represented by the open rectangular symbol, and a minimum value, which is represented by the solid rectangular symbol, with a continuous decrease of mass fluxes. The demand curves without active control show the spoon shape over the whole range of mass fluxes. The difference between the maximum and the minimum pressure drops is the oscillation amplitude of the unstable boiling flow, which first increases, attains the maximum value and then decreases, with continuous decrease of mass fluxes.
- The quasi-linear part of the demand curve with active control coincides with that without active control, indicating no effect of seed bubbles on the single-phase liquid flow in microchannels.

- The demand curves with active control display the chair shape over the whole range of mass fluxes. Demand curves show no bifurcation after they deviate from the linear part, indicating the quasi-steady boiling flow in microchannels.

- Generally, the pressure drops with active control are higher than those without active control at the same mass flux after they deviate from the linear part. The higher the seed bubble frequency, the higher the pressure drops.

- The linear part of the demand curve is shortened when the active control technique is used. The points at which the demand curves deviate from the linear part coincide into one point at different seed bubble frequencies. It is noted that the liquid may be superheated without active control due to the lack of nucleation sites on the channel wall surfaces. The introduction of seed bubbles evolves the two-phase flow only if the liquid temperature is higher than the saturation temperature, causing the demand curves to deviate from those without active control. Thus, no matter how many seed bubbles are injected in microchannels over a given period of time, the points at which the demand curves deviate from the linear part coincide into one point at different seed bubble frequencies. 


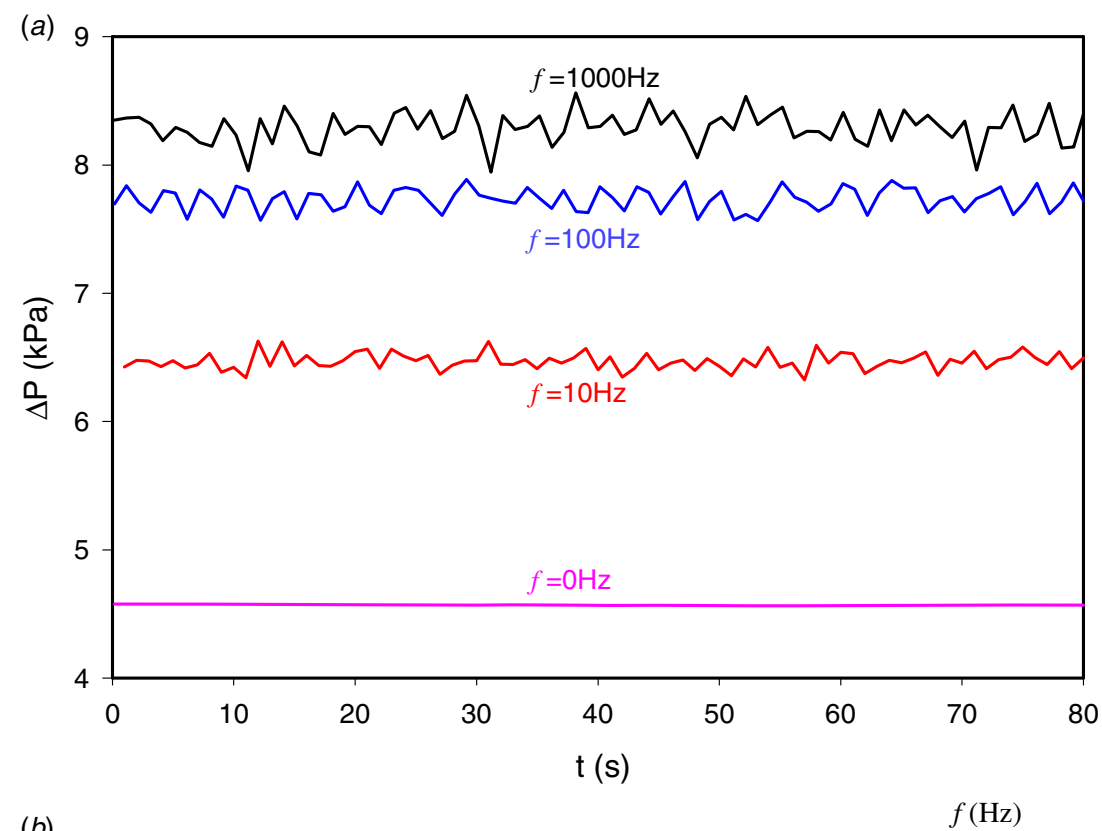

(b)

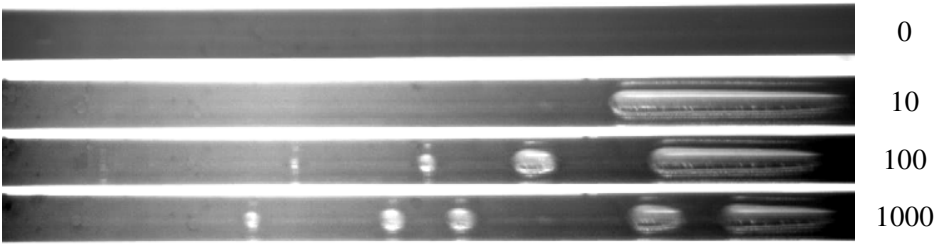

Figure 6. Transient pressure drops versus time with and without active control in region II (a) and typical flow patterns in the \#3 channel for $x_{\text {film }}$ from 2 to $6 \mathrm{~mm}(b)\left(G=517.89 \mathrm{~kg} \mathrm{~m}^{-2} \mathrm{~s}^{-1} ; q^{3}=374.61 \mathrm{~kW} \mathrm{~m}^{-2} ; B o=0.00063\right)$.

- The pressure drops at very small mass fluxes with and without active control approach to coincide into one point. This situation corresponds to high-vapor-mass qualities in microchannels.

In order to further identify the demand curves with and without active control, we re-plot figure 4(c) and focus the seed bubble frequencies at $f=0$ and $100 \mathrm{~Hz}$ in figure $5(a)$. Figure 5(b) shows the heating surface temperature at $x_{\text {film }}=$ $8.0 \mathrm{~mm}$ and $y=0$ (see figure 1). Temperatures at this location reach almost maximum values over the whole main heater surface. The observed phenomenon is summarized as follows.

- Four regions can be divided over the whole range of mass fluxes.

- For the flow without active control, regions I, II, III and IV are the subcooled liquid flow, the superheated liquid flow, the unsteady boiling flow and the vapor flow at extremely high vapor mass qualities or superheated vapor flow. There are not many data in region IV.

- For the flow with active control, regions I, II, III and IV are the subcooled liquid flow, the seed-bubble-triggered boiling flow (TBF), the seed-bubble-stabilized boiling flow (SBF) and the vapor flow, respectively.

- Both the TBF and the SBF are quasi-stable boiling flows with active control.

- Regions I and IV are identical for the flow with and without active control, indicating no effect of seed bubbles on both the single-phase liquid flow and the vapor flow.
In region I, seed bubbles have no effect on the subcooled liquid flow in microchannels. Flowing seed bubbles in liquids form bubbly flow. The void fraction is so small that the effect of seed bubbles on the flow and heat transfer cannot be identified. Assuming a diameter of $10 \mu \mathrm{m}$ and a generation frequency of $1000 \mathrm{~Hz}$ for seed bubbles flowing in liquid with a velocity of $1 \mathrm{~m} \mathrm{~s}^{-1}$, the void fraction is $6 \times 10^{-5}$. The condensation of seed bubbles in flowing subcooled liquid shrinks the seed bubble size and further decreases the effect of seed bubbles on the flow and heat transfer in microchannels.

Region II refers to the superheated liquid flow in microchannels without active control. Injection of seed bubbles triggers boiling heat transfer, converting the superheated liquid flow into two-phase flow in microchannels. Thus, the flow and heat transfer performance without active control is significantly different from that with active control. Region III is the self-sustained unstable boiling flow without active control. The nucleation sites on channel wall surface are not enough to reach thermal equilibrium between liquid and vapor phases. Injection of seed bubbles decreases and controls the thermal non-equilibrium between liquid and vapor phases.

Region IV considers the vapor flow at high-vapor-mass qualities. The flow pattern is that of either elongated bubble flow or annular flow. Heat transfer is well maintained by a thin liquid film between the channel wall surface and the vapor core. Seed bubbles are merged by the elongated bubble 

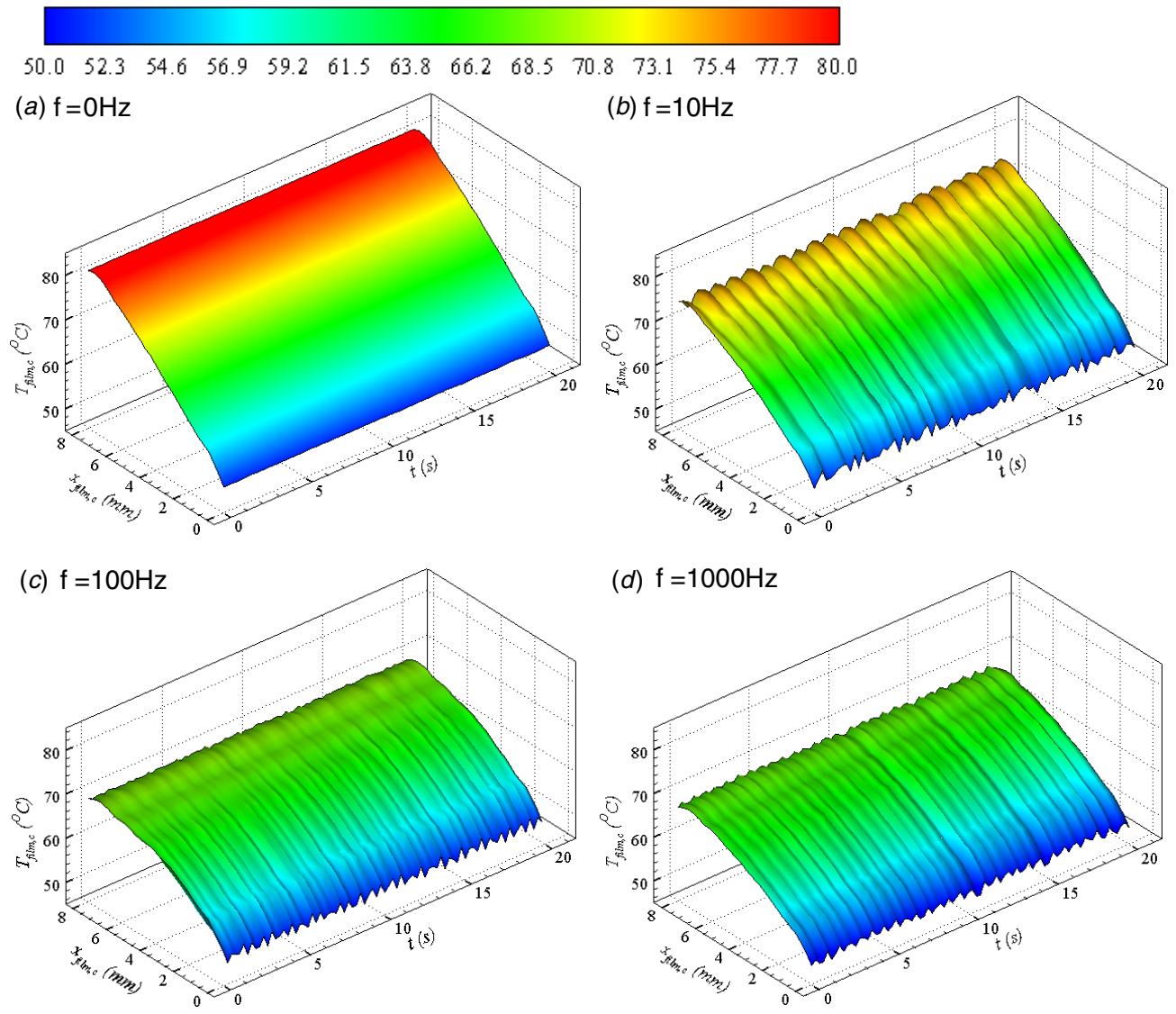

Figure 7. Transient temperatures on the main heater surface at $y=0$ in region II $\left(G=517.89 \mathrm{~kg} \mathrm{~m}^{-2} \mathrm{~s}^{-1}, q 3=374.61 \mathrm{~kW} \mathrm{~m} \mathrm{~m}^{-2}, B o=\right.$ $0.00063 ;(a)-(d)$ correspond to $0,10,100$ and $1000 \mathrm{~Hz})$.

or the vapor core. They have no effect on the flow and heat transfer due to their smaller size compared with the elongated bubble or the vapor core.

We define the TBF because superheated liquid flow exists in microchannels without active control. Injection of seed bubbles successfully induces a quasi-steady boiling flow in microchannels. We define the SBF because self-sustained unsteady boiling flow exists in microchannels without active control. Injection of seed bubbles switches an unsteady boiling flow to a quasi-steady boiling flow. Both the TBF and the SBF decrease the thermal non-equilibrium between liquid and vapor phases.

For the flow without active control, heater surface temperatures evolve the values below the saturation temperature in region $I$ and the values above the saturation temperature in region II. With further decreases of mass fluxes less than that at the OFI (onset of flow instability) point, temperatures have maximum and minimum values corresponding to the unsteady boiling flow in region III. The oscillation amplitudes of temperatures increase, attain maximum values and then decrease with continuous decreases of mass fluxes in region III.

For the flow with active control, temperatures decrease in regions II and III compared with the flow without active control, indicating significant heat transfer enhancement. Because the flow is quasi-steady guided by seed bubbles, the uncertainties of temperatures are small; thus, only one value is marked in the figure for each mass flux.

\subsection{The $T B F$}

This section describes the TBF with active control. Figure 6(a) shows the transient pressure drops with and without active control for the run of $G=517.89 \mathrm{~kg} \mathrm{~m}^{-2} \mathrm{~s}^{-1}$ and $q=$ $374.61 \mathrm{~kW} \mathrm{~m}^{-2}$. The flow behaves as an exactly stable pressure drop without active control $(f=0)$. When seed bubbles are injected in microchannels, pressure drops oscillate with small amplitudes in the range of $0.1-0.5 \mathrm{kPa}$ for seed bubble frequencies of 10,100 and $1000 \mathrm{~Hz}$, referring to the quasi-steady TBF. The thermal non-equilibrium, i.e. the temperature difference between liquid and vapor phases, decreases with increase of seed bubble frequencies. Thus, much energy can be transferred from the superheated liquid to the vapor, leading to the increased pressure drops with increase of seed bubble frequencies.

Figure $6(b)$ shows the flow patterns with and without active control. It is seen that indeed no bubbles are observed without active control ( $f=0$; see the first image in figure $6(b)$ ). Generally, spherical bubbles and elongated bubbles coexist in microchannels with active control (see figure $6(b)$ ). More bubbles are observed with increases of seed bubble frequencies $(f)$. Flow patterns are similar to those shown in figure $6(b)$ at any time. However, dynamic 

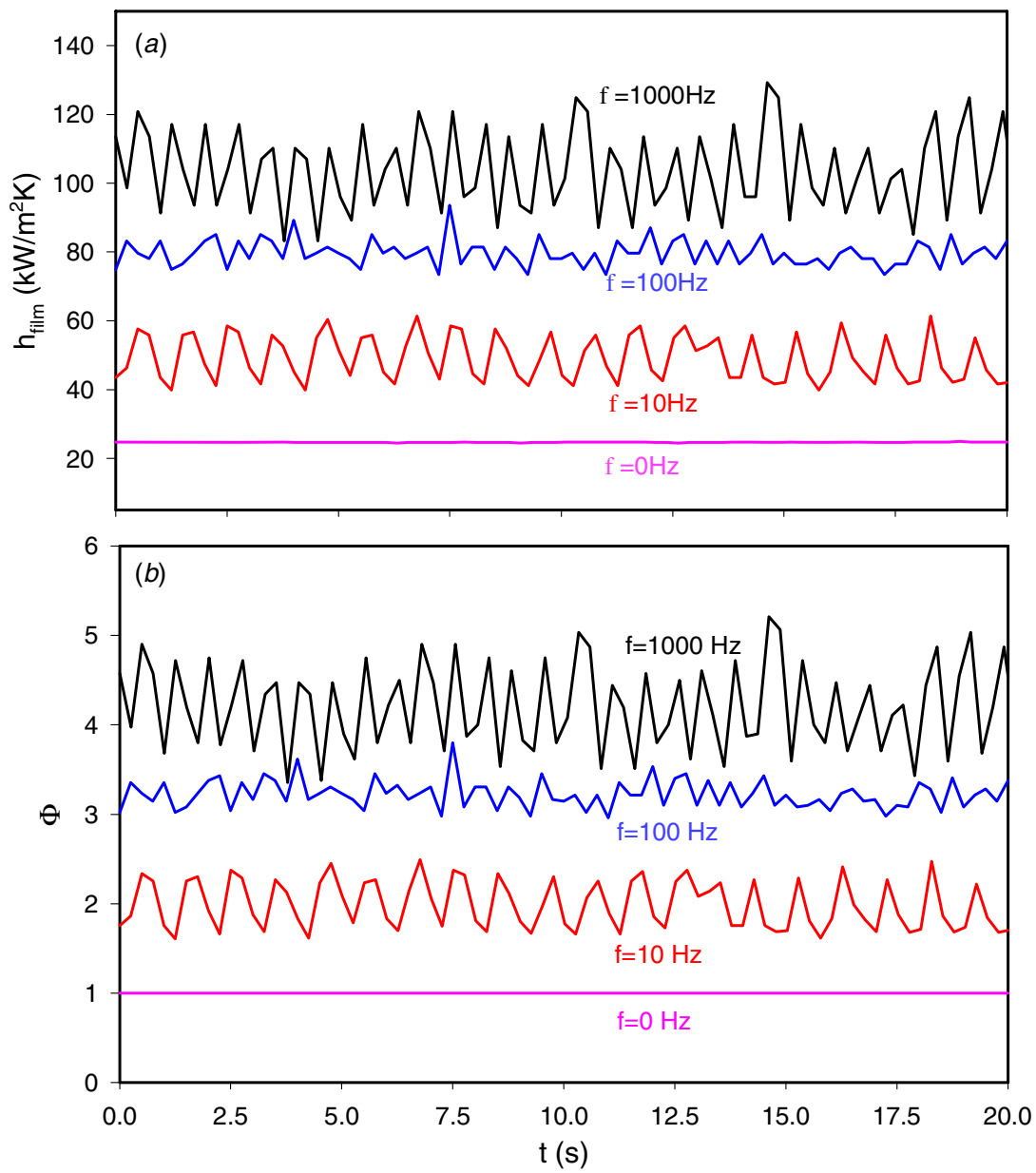

Figure 8. Transient heat transfer coefficients at $x_{\text {film }}=8 \mathrm{~mm}$ in region II $(a)$ and heat transfer enhancement ratio at that location $(b)(G=$ $\left.517.89 \mathrm{~kg} \mathrm{~m}^{-2} \mathrm{~s}^{-1} ; q 3=374.61 \mathrm{~kW} \mathrm{~m}^{-2} ; B o=0.00063\right)$.

evolution of flow patterns exists in microchannels, causing small-amplitude oscillations of pressure drops; see figure $6(a)$.

Figure 7 examines the main heater surface temperatures over the whole heating length of $8.0 \mathrm{~mm}$ against time. A quasi-linear increase of heater surface temperatures along the flow direction is shown in figure 7(a) without active control, displaying no change versus time. Temperatures attain maximum values at the end of the heating area, i.e. at $x_{\text {film }}=$ $8.0 \mathrm{~mm}$, which are about $82{ }^{\circ} \mathrm{C}$, quite a bit higher than the saturation temperature of $64.7^{\circ} \mathrm{C}$ at atmospheric pressure. A simple calculation of the liquid temperature distribution along the flow direction gave positive superheats in the downstream part of microchannels.

Figures $7(b)-(d)$ illustrate the heater surface temperatures for the three seed bubble frequencies of 10,100 and $1000 \mathrm{~Hz}$, respectively. The following phenomena are observed.

- Temperatures are lower than those without active control, indicating heat transfer enhancement.

- Temperature gradients decrease along the flow direction.

- The higher the seed bubble frequencies, the more the heater surface temperatures decrease.

- The oscillation amplitudes of the quasi-stable temperatures are less than $1-3{ }^{\circ} \mathrm{C}$.
- The maximum temperatures near the end of the heater surface are about $66-69{ }^{\circ} \mathrm{C}$, inferring a very small temperature difference between the wall surface and the liquid, at the high seed bubble frequencies of 100 and $1000 \mathrm{~Hz}$.

Heat transfer coefficients and heat transfer enhancement ratios are plotted versus time in figure 8 . These parameters are defined at the end of the heating area, i.e. at $x_{\text {film }}=$ $8.0 \mathrm{~mm}$. The stable heat transfer coefficients are $25 \mathrm{~kW} \mathrm{~m}{ }^{-2} \mathrm{~K}^{-1}$ for the no active control case $(f=0)$. However, they are much higher with active control than those without active control. The higher the seed bubble frequencies, the higher the heat transfer coefficients. Corresponding to the small-amplitude oscillation of flow patterns and heater surface temperatures, the heat transfer coefficients vary with time. For example, heat transfer coefficients change in the range of 100$120 \mathrm{~kW} \mathrm{~m}{ }^{-2} \mathrm{~K}^{-1}$ for the seed bubble frequency of $1000 \mathrm{~Hz}$. Thus, the oscillation amplitude of $20 \mathrm{~kW} \mathrm{~m}{ }^{-2} \mathrm{~K}^{-1}$ is about $20 \%$ of the average value. The slightly larger oscillation amplitude is due to the small temperature difference between the heater surface temperature and the saturation temperature of fluid there. Heat transfer coefficients with active control are several times those without active control. Even at the seed bubble frequency of $10 \mathrm{~Hz}$, the heat transfer enhancement 

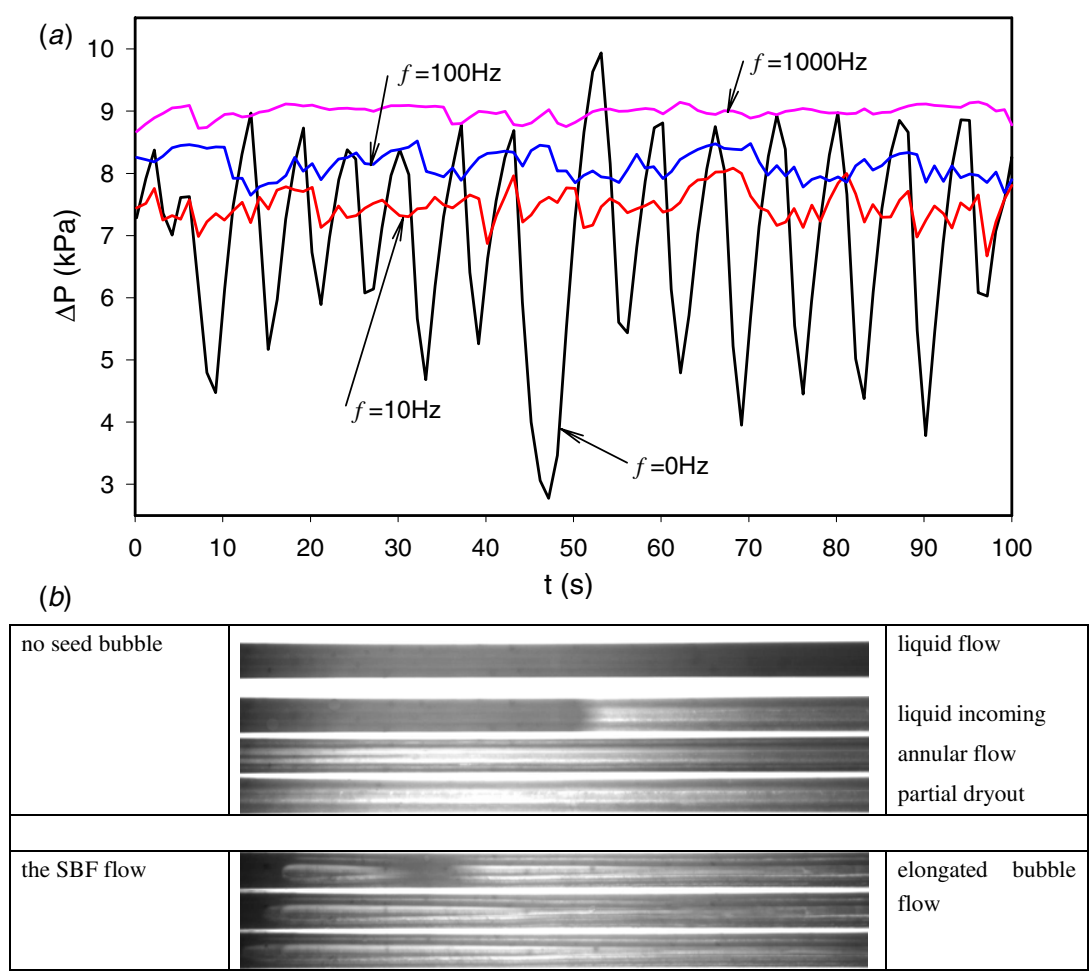

Figure 9. Transient pressure drops and typical flow patterns in the \#3 channel for $x_{\text {film }}$ from 2 to $6 \mathrm{~mm}$ with and without active control in region III $\left(G=254.58 \mathrm{~kg} \mathrm{~m}^{-2} \mathrm{~s}^{-1} ; q 3=374.61 \mathrm{~kW} \mathrm{~m}^{-2} ; B o=0.00128\right)$.

ratio reaches 2 . For the seed bubble frequency of $1000 \mathrm{~Hz}$, the values of the heat transfer enhancement ratios reach 4 and 5 (see figure $8(b)$ ).

\subsection{The $S B F$}

Different from the phenomenon described in section 4.3, the unsteady boiling flow is self-sustained in microchannels without active control. It is seen from figure $9(a)$ that the pressure drops oscillate in the range of $3-10 \mathrm{kPa}$, with the maximum amplitude of $7 \mathrm{kPa}$, without active control. Considering the liquid flow in heated microchannels, bubble nucleation does not appear until the heating surface temperature and the bulk liquid temperature are significantly superheated. Once boiling is triggered, the superheated liquid releases its stored energy to vapor phase through the nucleated bubble interface in a short time. A sharp pressure increase in the vapor core makes the fluid travel in both downstream and upstream directions. The vapor growth and pressure rise stage is complete when the superheated liquid completely releases its stored energy. Note that an external pumping pressure is always applied on the fluid, causing the subcooled liquid to refill the microchannels. It will take some time for the incoming liquid to reach the superheated bubble nucleation temperature again. The above processes are repeated in time sequence, causing the alternating flow pattern transitions in microchannels. Kandlikar et al (2006) and $\mathrm{Xu}$ et al (2009) noted that the flow boiling process suffers from severe instabilities due to the nucleation of vapor bubbles in a superheated liquid environment in a minichannel or a microchannel. In summary, the severe flow instability in smooth microchannels is caused by the thermal nonequilibrium between vapor and liquid phases.

Seed bubbles significantly suppress flow instabilities in microchannels. As shown in figure $9(a)$, pressure drops for the seed bubble frequencies of 10,100 and $1000 \mathrm{~Hz}$ had quite small oscillation amplitudes compared with those without active control, leading to the quasi-stable boiling flow. The higher the seed bubble frequencies, the higher the pressure drops across microchannels, due to the vapor produced in microchannels when seed bubble frequencies increase. However, the pressure drops with active control seldom exceed the maximum value without active control.

Typical flow patterns are shown in figure $9(b)$ with and without active control. The alternative liquid flow/annular flow/partial dried-out flow sequentially exist in microchannels without active control (see figure $9(b)$ ). It is noted that the alternative flow patterns depend on the mass flux, the heat flux and the working fluid for the self-sustained unsteady boiling flow, which may deviate from the photographs shown in figure $9(b)$ for different runs. However, injection of seed bubbles yields a quasi-steady elongated bubble flow at any time (see figure $9(b)$ ).

Figure 10 shows the effect of active control using seed bubbles on the heater surface temperatures. The heater surface temperatures with large amplitude without active control, represented by figure $10(a)$, significantly decrease by using seed bubble injections, represented by figures $10(b)-(d)$. Heater surface temperature gradients decrease significantly along the flow direction. 


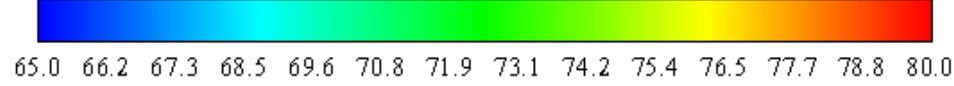

(a) $\mathrm{f}=\mathrm{OHz}$
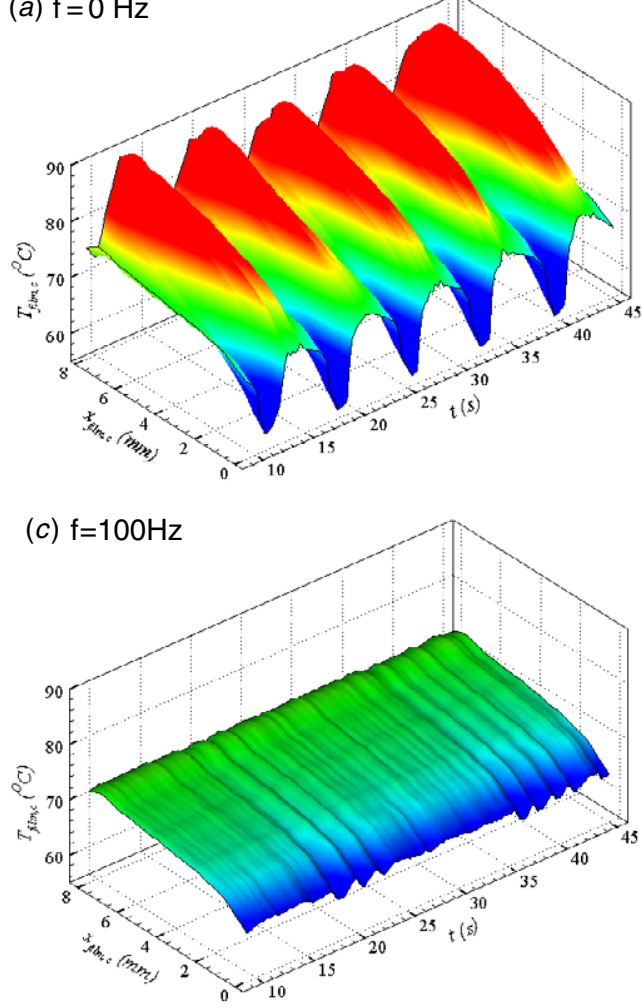

(b) $\mathrm{f}=10 \mathrm{~Hz}$
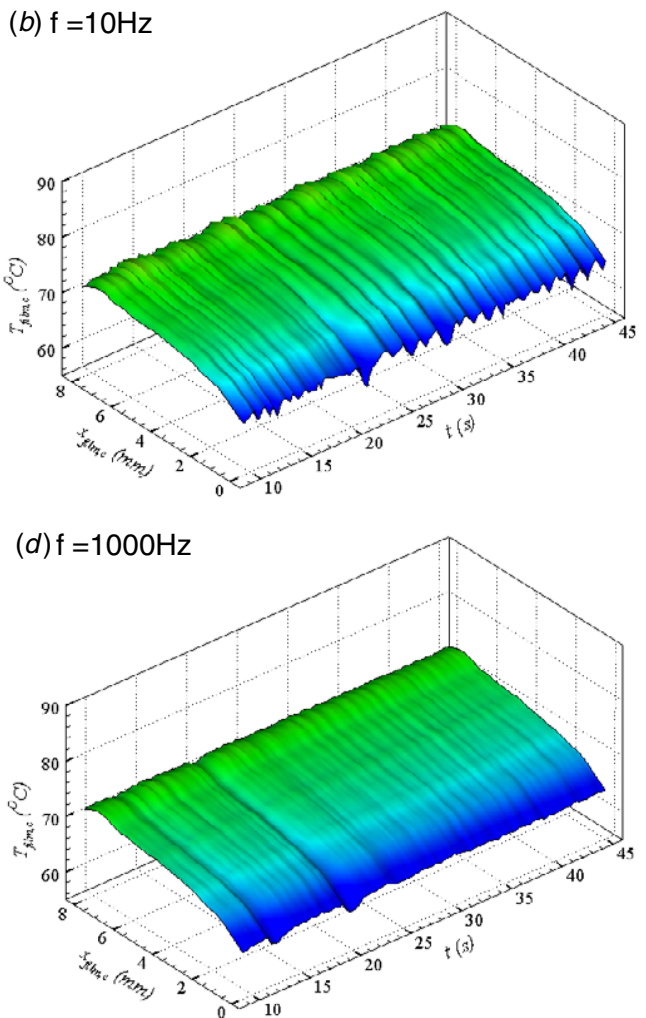

Figure 10. Transient temperatures on the main heater surface at $y=0$ in region III $\left(G=254.58 \mathrm{~kg} \mathrm{~m}^{-2} \mathrm{~s}^{-1} ; q 3=374.61 \mathrm{~kW} \mathrm{~m}^{-2} ; B o=\right.$ $0.00128)$.
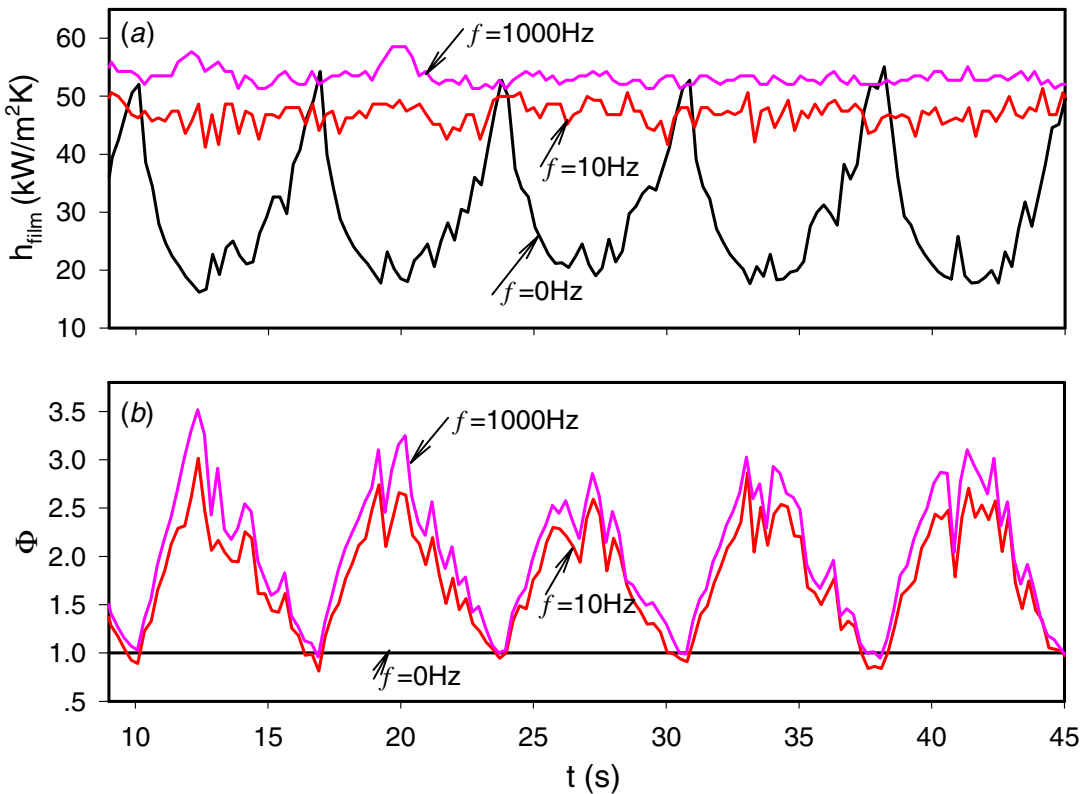

Figure 11. Transient heat transfer coefficients at $x_{\text {film }}=8.0 \mathrm{~mm}$ in region III $(a)$ and heat transfer enhancement ratio at that location (b) $\left(G=254.58 \mathrm{~kg} \mathrm{~m}^{-2} \mathrm{~s}^{-1} ; q 3=374.61 \mathrm{~kW} \mathrm{~m}^{-2} ; B o=0.00128\right)$.

Figure 11 shows the transient heat transfer coefficients and the heat transfer enhancement ratios at $x_{\text {film }}=8.0 \mathrm{~mm}$ and $y=0$. Heat transfer coefficients vary from $16-18$ to about $50 \mathrm{~kW} \mathrm{~m} \mathrm{~m}^{-2} \mathrm{~K}^{-1}$ without active control, but they are about $50 \mathrm{~kW} \mathrm{~m} \mathrm{~m}^{-2} \mathrm{~K}^{-1}$ and do not change too much with active control. The heat transfer enhancement ratios attain the dynamic values of 1-3.5 with active control. 


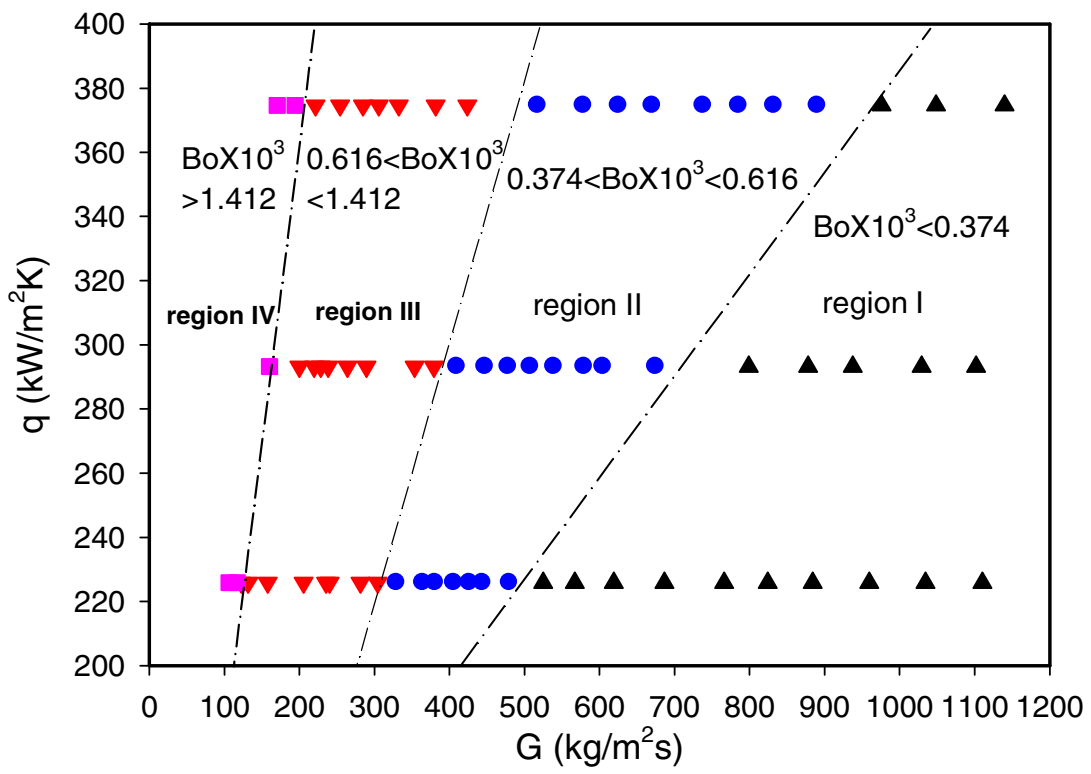

Figure 12. The four heat transfer regions with and without active control based on heat fluxes and mass fluxes. (For the flow without active control, regions I, II, III and IV are the subcooled liquid flow, the superheated liquid flow, the unstable boiling flow and the vapor flow at high-vapor-mass qualities. Alternatively, for the flow with active control, regions I, II, III and IV are the subcooled liquid flow, the seed bubble TBF, the seed bubble SBF, and the vapor flow at high-vapor-mass qualities.)
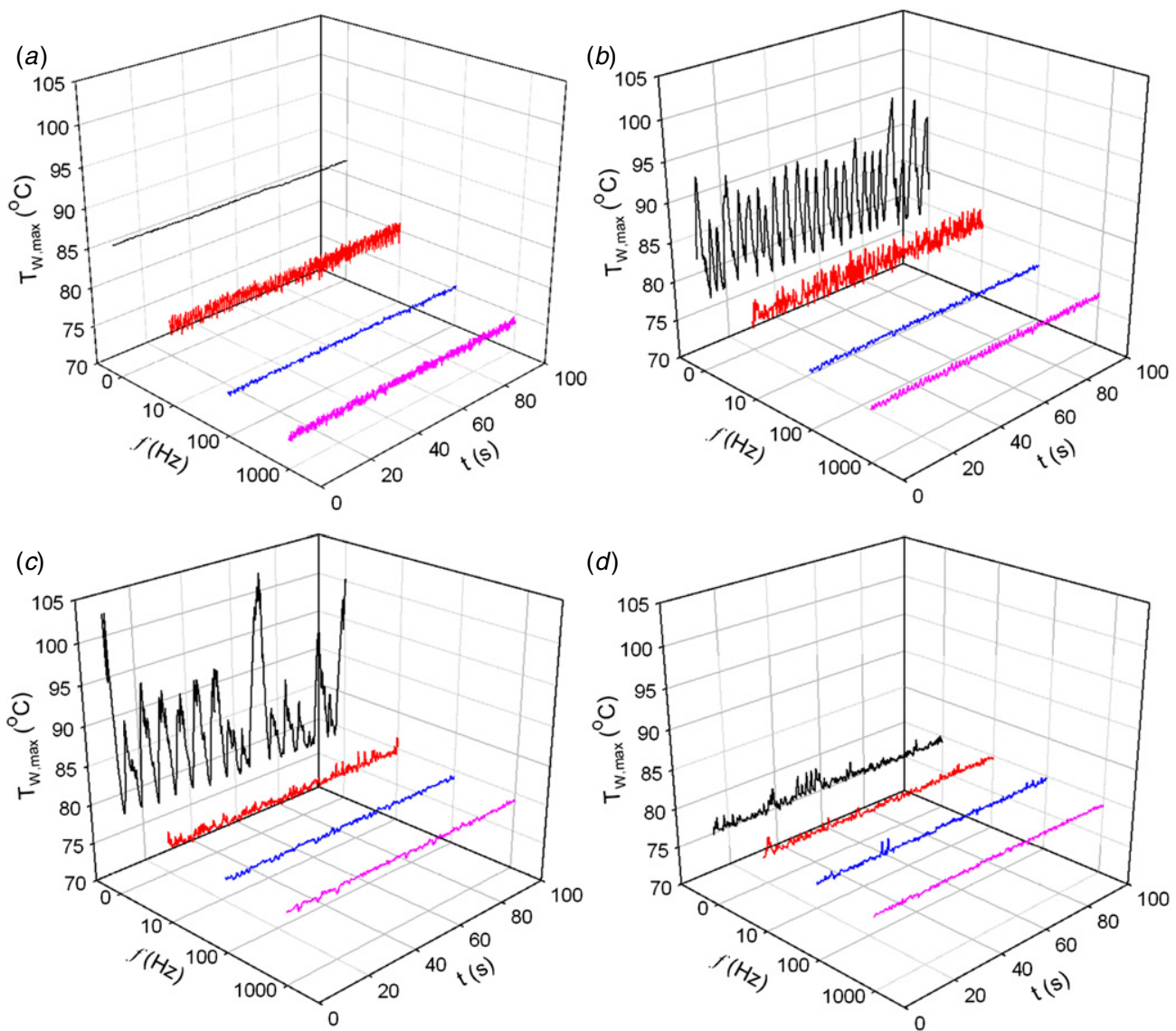

Figure 13. The maximum temperatures on the main heater surface with and without active control at different boiling numbers. (a) $G=$ $517.89 \mathrm{~kg} \mathrm{~m}^{-2} \mathrm{~s}^{-1} ; q=374.61 \mathrm{~kW} \mathrm{~m}^{-2} ; B o=0.000629$. (b) $G=332.55 \mathrm{~kg} \mathrm{~m}^{-2} \mathrm{~s}^{-1} ; q=374.61 \mathrm{~kW} \mathrm{~m}^{-2} ; B o=0.000980$. (c) $G=$ $254.57 \mathrm{~kg} \mathrm{~m}^{-2} \mathrm{~s}^{-1} ; q=374.61 \mathrm{~kW} \mathrm{~m}^{-2} ; B o=0.001280$. (d) $G=170.64 \mathrm{~kg} \mathrm{~m}^{-2} \mathrm{~s}^{-1} ; q=374.61 \mathrm{~kW} \mathrm{~m}^{-2} ; B o=0.001909$. 
4.5. The flow region map depending on heat fluxes and mass fluxes

Figure 12 summarizes the flow region map with mass flux and heat flux as the two coordinates. The four regions take place at $B o<0.374 \times 10^{-3}$ for region I, $0.374 \times 10^{-3}<$ Bo $<0.616 \times 10^{-3}$ for region II, $0.616 \times 10^{-3}<B o<$ $1.412 \times 10^{-3}$ for region III and $B o>1.412 \times 10^{-3}$ for region IV. For the flow without active control, regions I, II, III and IV are the subcooled liquid flow, the superheated liquid flow, the unsteady boiling flow and the vapor flow at highvapor-mass qualities, respectively. For the flow with active control, the four regions are the subcooled liquid flow, the TBF, the SBF and the vapor flow at high-vapor-mass qualities, respectively. Seed bubbles have no effect on the flow and heat transfer in regions I and IV. In region II, seed bubbles convert a superheated liquid flow into a quasi-steady boiling flow. In region III, seed bubbles convert a self-sustained unsteady boiling flow into a quasi-stable boiling flow.

As noted before, the maximum heater surface temperatures appear nearly at the end of the heating area, i.e. at $x_{\text {film }}=8.0 \mathrm{~mm}$. Figure 13 shows the maximum heater surface temperatures for four boiling numbers, in which figure 13(a) is for region II, figures $13(b)$ and $(c)$ for region III and figure 13(d) for region IV. Seed bubbles decrease the heater surface temperatures in figure 13(a) and convert the unsteady boiling flow ( $f=0 \mathrm{~Hz}$ ) into a quasi-stable flow in figures $13(b)$ and $(c)$. There is no apparent influence of seed bubbles on the flow and heat transfer in figure 13(d). Figure 13 also indicates that the difference of heater surface temperatures between $f=100 \mathrm{~Hz}$ and $1000 \mathrm{~Hz}$ is small, inferring the saturation seed bubble frequency of $1000 \mathrm{~Hz}$.

We identified the significant heat transfer enhancement by seed bubbles. Due to the lack of nucleation sites on channel wall surfaces, the flow is in non-equilibrium state, i.e. the liquid is superheated while the vapor is saturated. The introduction of seed bubbles decreases the thermal non-equilibrium between liquid and vapor phases. The void fraction with active control should be larger than that without active control, maintaining a good thin film evaporation heat transfer mode to enhance heat transfer. The time-spatial-varied void fractions increase with increase in seed bubble frequencies. Thus, the higher the seed bubble frequencies, the more the heater surface temperatures decrease, and the heat transfer enhancement ratios increase. When the seed bubble frequencies increase to a specific value, such as 100 or $1000 \mathrm{~Hz}$ in this paper, the flow approaches equilibrium. Thus, the saturation seed bubble frequency attains the maximum heat transfer enhancement ratios. This explanation is suitable for both the TBF and the SBF.

\section{Conclusions}

The seed bubble technique is used as an effective active control strategy for the flow and heat transfer in silicon microchannels. A single miniature bubble is produced on a microheater surface during one pulse. The seed bubble frequency controls the thermal non-equilibrium between vapor and liquid phases. The experiments were performed over a wide range of mass fluxes. The demand curves of pressure drops versus mass fluxes were examined. The following conclusions can be drawn.

- Over the wide range of mass fluxes, the demand curves of pressure drops versus mass fluxes can be divided into four regions.

- Regions I, II, III and IV are the subcooled liquid flow, the superheated liquid flow, the unstable boiling flow and the vapor flow at high-vapor-mass qualities without active control.

- Regions I, II, III and IV are the single-phase liquid flow, the TBF, the SBF and the vapor flow at high-vapor-mass qualities with active control.

- Seed bubbles have no influence on the flow and heat transfer in regions I and IV.

- Seed bubbles convert a superheated liquid flow into a quasi-steady boiling flow in region II.

- Seed bubbles convert an unstable boiling flow into a quasisteady boiling flow in region III.

- Heat transfer is significantly enhanced in regions II and III.

- The linear part of the demand curves is shortened when the seed bubble technique is used. The points at which the demand curves deviate from the linear part coincide into one point at different seed bubble frequencies.

- Seed bubble frequency is the key parameter that influences the flow and heat transfer in microchannels. The higher the seed bubble frequency, the more the heater surface temperatures decrease in regions II and III.

\section{Acknowledgments}

This work was supported by the National Science Fund for Distinguished Young Scholars from the National Natural Science Foundation of China (no 50825603).

\section{References}

Xu J, Liu G, Zhang W, Li Q and Wang B 2009 Seed bubbles stabilize flow and heat transfer in parallel microchannels Int. J. Multiph. Flow 35 773-90

Kandlikar S G 2002 Fundamental issues related to flow boiling in minichannels and microchannels Exp. Therm. Fluid Sci. 26 389-407

Kandlikar S G, Kuan W K, Willistein D A and Borrelli J 2006 Stabilization of flow boiling in microchannels using pressure drop elements and fabricated nucleation sites Trans. ASME, J. Heat Transfer 128 389-95

Kandlikar S G, Mizo V R, Cartwright M D and Ikenze E 1997 Bubble nucleation and growth characteristics in subcooled flow boiling of water HTD-Vol. 342, ASME Proc. 32nd Natl. Heat Transfer Conf. vol 4 pp 11-8

Kuo C J and Peles Y 2009 Pressure effects on flow boiling instabilities in parallel microchannels Int. J. Heat Mass Transfer 52 271-80

Li J and Cheng P 2004 Bubble cavitation in a microchannel Int. J. Heat Mass Transfer 47 2689-98 
Lin L W, Pisano A P and Carey V P 1998 Microscale thermal bubble formation: thermophysical phenomenon and applications Microscale Thermophys. Eng. 271-85

Liu D, Lee P S and Garimella S V 2005 Prediction of the onset of nucleate boiling in microchannel flow Int. J. Heat Mass Transfer 48 5134-49

Thome J R and Dupont V 2007 Heat transfer assembly European Patent EP 1,779,052 B1
Wu H Y, Cheng P and Wang H 2006 Pressure drop and flow boiling instabilities in silicon microchannel heat sinks J. Micromech. Microeng. 18 2138-46

Yaws C L 1999 Chemical Properties Handbook (New York: McGraw-Hill)

Yu C K, Lu D C and Cheng T C 2006 Pool boiling heat transfer on artificial micro-cavity surfaces in dielectric fluid FC-72 J. Micromech. Microeng. 16 2092-9 